\title{
Echovírus 6 associado à doença exantemática
}

\author{
Echovirus 6 associated with exanthematic disease
}

\author{
Ana Paula de Torres Santos ${ }^{1}$, Denise Hage Russo ${ }^{1}$, Bráulio Caetano Machado ${ }^{1}$, \\ Adriana Luchs ${ }^{1}$, Maria do Carmo Sampaio Tavares Timenetsky ${ }^{1}$ \\ e Rita de Cássia Compagnoli Carmona ${ }^{1}$
}

\begin{abstract}
RESUMO
Exantema viral é considerado problema comum em regiões tropicais, afetando principalmente crianças. Diversos exantemas cutâneos estão associados a infecções por Enterovirus. Amostras biológicas provenientes de uma criança apresentando exantema generalizado foram enviadas ao Laboratório de Vírus Entéricos do Instituto Adolfo Lutz para a realização do diagnóstico laboratorial. Amostra viral isolada em RD (buman rhabdomyosarcoma cells) foi submetida à reação em cadeia pela polimerase apresentando um produto de 437 pares de base, característico de gênero Enterovirus. 0 sorotipo echovirus 6 (E-6) foi identificado por ensaio de imunofluorescência indireta. Em adição, as amostras pareadas de soro apresentaram soroconversão para E-6. Até o momento, não há relatos do envolvimento de E-6 associado a doenças exantemáticas no Brasil, enfatizando a importância da vigilância epidemiológica para essas doenças e suas complicações.
\end{abstract}

Palavras-chaves: Enterovirus. Doença exantemática. Echovírus. Exantema viral.

\begin{abstract}
Viral exanthems are a common problem in tropical regions, particularly affecting children. Various skin rashes have been reported in acute infections caused by Enterovirus. Biological samples from a child who presented generalized rashes were sent to the Enteric Virus Laboratory of the Adolfo Lutz Institute for laboratory diagnosis to be performed. A viral sample isolated from RD (human rhabdomyosarcoma cells) was subjected to the polymerase chain reaction and showed a 437-base pair product that was characteristic of the Enterovirus genus. Echovirus 6 (E-6) serotype was identified using the indirect immunofluorescence test. In addition, paired serum samples presented seroconversion to E-6. So far, there have not been any reports of E-6 involvement in exanthematic diseases in Brazil. Thus, the importance of epidemiological surveillance for these diseases and their complications is emphasized.
\end{abstract}

Key-words: Enterovirus. Exanthematic disease. Echovirus. Viral exanthems..

Os picornavírus são a causa mais freqüente de infecções humanas em todo o mundo. A família Picornaviriade compreende 9 gêneros: Enterovirus, Rhinovirus, Aphthovirus, Hepatovirus, Parechovirus, Erbovirus, Kobuvirus, Cardiovirus e Teschvirus. Dentro da família Picornaviriade, seis gêneros acometem humanos: Rhinovirus, Eterovírus Humano (EVH), Hepatovirus, Parechovirus, Cardiovirus e Kobuvirus. 0 gênero Enterovirus consiste em 65 sorotipos humanos, os quais são classificados em 5 espécies: Poliovirus e enterovirus humano de $\mathrm{A}$ a $\mathrm{D}^{1826}$.

Surtos de EVH geralmente ocorrem durante o verão e outono, mas infecções esporádicas podem ser observadas ao longo de todo 0 ano ${ }^{1922}$. 0 enterovirus humano é adquirido através de transmissão fecal-oral e, de forma menos comum pela via respiratória. Esses vírus são responsáveis por uma variedade de manifestações clínicas, afetando diversos órgãos do corpo. Uma vez presente, as manifestações clínicas, variam desde doença febril indiferenciada até paralisias graves e permanentes, algumas vezes fatais. A maior parte das infecções por EVH são assintomáticas. Dentre as síndromes clínicas causadas por EVH destacam-se aquelas que afetam o sistema nervoso central, pulmões e coraçãa ${ }^{22}$. Síndromes como poliomielite, meningite, herpangina, conjuntivite e doenças respiratórias, gastrointestinais e de mão, pé e boca são as mais freqüentemente associadas a $\mathrm{EVH}^{14}$. Vale ressaltar que encefalite, miocardite e sepse enteroviral neonatal podem estar relacionadas com o desenvolvimento de algumas doenças crônicas (e.g. diabetes tipo I e cardiomiopatia dilatada $)^{11}$.

Um grande número de doenças virais apresenta manifestações cutâneas: sarampo, rubéola, adenovírus, enterovírus nãopoliovírus, vírus respiratórios, dengue, vírus Epstein-Barr, herpes vírus tipos 6 e 7, assim como parvovírus B19 ${ }^{820}$. Em vários casos, é o principal marcador da enfermidade, enquanto em outros pode

\footnotetext{
1. Laboratório de Vírus Entéricos, Serviço de Virologia, Divisão de Biologia Médica, Instituto Adolfo Lutz, São Paulo, SP.

Endereço para correspondência: Drª Rita de Cássia Compagnoli Carmona. Lab. de Vírus Entéricos/Serviço de Virologia/Instituto Adolfo Lutz. Av. Dr. Arnaldo 355 , 01246-902 São Paulo, SP

Tel: 5511 3068-2909; Fax: $55113088-3041$

e-mail: rcarmona@ial.sp.gov.br

Recebido para publicação em 12/05/2008

Aceito em 09/10/2008
} 
aparecer meramente como uma manifestação clínica incidental; contudo quando o exantema ocorre torna-se um mecanismo auxiliar para o diagnóstico e sua importância é reconhecida desde a antiguidade ${ }^{3}$.

Inúmeros exantemas cutâneos estão associados a infecções agudas provocadas por Enterovirus. Os exantemas são geralmente transientes, associados com febre e outros sintomas ${ }^{7}$.

0 objetivo do presente trabalho foi realizar o diagnóstico diferencial e identificar o EVH, através do isolamento viral e técnicas imunológicas e moleculares, como o agente etiológico responsável por um caso de doença exantemática ocorrido no mês de janeiro de 2007 na Cidade de São Paulo, SP, Brasil.

\section{RELATO DE CASO}

Em Janeiro de 2007, o Laboratório de Vírus Entéricos do Instituto Adolfo Lutz recebeu amostras de fezes e soro pareados provenientes de uma criança do sexo masculino de 1 ano e 11 meses de idade, internada no Instituto de Infectologia Emílio Ribas e nativa da Cidade de Itapevi, SP, Brasil. A criança apresentou febre de $39^{\circ} \mathrm{C}$, crises convulsivas, exantema generalizado, incluindo palma das mãos e planta dos pés, além de perda de apetite e adinamia. 0 diagnóstico inicial foi uma infecção viral não específica caracterizada por lesões de pele e mucosas. Foram descartadas através de testes laboratoriais as suspeitas clínicas: varicela, rubéola, caxumba, mononucleose, toxoplasmose, citomegalovírus e dengue. Não houve um diagnóstico médico conclusivo.

0 exantema foi caracterizado inicialmente por lesões micropapulares na face, de coloração avermelhada, pruriginosa e indolor, disseminando-se pelo corpo em menos de 24 horas. Membros superiores e inferiores apresentavam pápulas eritematosas em alvo e algumas coalescentes. Posteriormente, as lesões apresentaram um leve prurido, fato não observado inicialmente. Pele áspera e apresentando exantema maculopapuloso também foi observado. A criança havia apresentado febre há 10 dias, sendo medicada com dipirona e amoxicilina em outro serviço sem melhora de quadro.

Exames laboratoriais. Isolamento viral e identificação: amostras de fezes foram clarificadas através de centrifugação a $10.000 \mathrm{xg} / 60$ minutos a $4^{\circ} \mathrm{C}$; antibióticos (estreptomicina e penicilina $[50 \mathrm{mg}]$ ) foram adicionados e o sobrenadante estocado a $-70^{\circ} \mathrm{C}$ até a inoculação $(0,1 \mathrm{e}$ $0,2 \mathrm{~mL} /$ tubo) em 3 diferentes linhagens celulares: RD (buman rhabdomyosarcoma cells, ATCC-CCL-136), HEp2 (buman larynx carcinoma cells, ATCC-CCL-23) e Vero (African green monkey kidney cells, ATCC-CCL-81) contendo meio de manutenção (Eagle + L15, Eagle + ANNE + piruvato e meio 199, respectivamente). Os tubos foram mantidos a $35-37^{\circ} \mathrm{C}$. As culturas foram observadas em microscópio invertido diariamente, objetivando visualizar a presença de efeito citopático (ECP) viral. Foram realizadas passagens sucessivas do material inoculado até o aparecimento ou não do ECP característico? .

Ensaio de imunofluorescência indireta: a cultura de célula que apresentou em torno de 75\% de ECP, teve as células removidas mecanicamente com o auxílio de um scraper e a suspensão celular transferida para uma lâmina de vidro, a qual foi seca e fixada com acetona. Em seguida, foi submetida à IFI, utilizando anticorpos monoclonais específicos comercialmente disponíveis (Chemicon International Inc, Temecula, CA/USA) para o gênero (Enterovirus), grupos (echovírus (E), coxsackievírus B (CV-B), enterovírus e poliovírus) e sorotipos. As lâminas foram examinadas com auxilio de um microscópio epifluorescente ${ }^{1}$.

Transcriptase resversa - reação em cadeia pela polimerase: 0 RNA viral foi extraído com Trizol@ LS (Invitrogen, Carlsbad, CA, USA) e clorofórmio a partir de vírus isolado, seguindo as instruções do fabricante. Após centrifugação a $12.000 x g$, a fase aquosa foi retirada e a precipitação realizada com álcool isopropílico. 0 precipitado de RNA foi lavado com etanol $75 \%$. No final do procedimento, o RNA foi rapidamente seco e ressuspendido em água Milli-Q; RNAsin [10U] foi adicionado e o RNA estocado a $-70^{\circ} \mathrm{C}$. 0 cDNA foi sintetizado a partir do RNA extraído e da mistura: $\mathrm{MgCl}_{2} 50 \mathrm{mM}$; tampão PCR 10X, dNTP 1,25nM, primer AS1/S1 20 $\mu \mathrm{M} / \mu \mathrm{L}$, super script II RNAse trancriptase reversa $2 \mu \mathrm{L}$; TaqQ DNA polimerase $2,5 \mathrm{U} / \mu \mathrm{L}$, RNAsin [10U] 40U/ $\mu \mathrm{L}$ e água Milli-Q. As reações de amplificação foram realizadas no termociclador gene Amp PCR System 9600 Perkin Elmer (Perkin-Elmer Corporation, Norwalk, CT, USA) com a seguinte programação: $\left(42^{\circ} \mathrm{C} / 1\right.$ hora $)+\left(95^{\circ} \mathrm{C} / 5\right.$ minutos $)+$ 25 ciclos $\left(94^{\circ} \mathrm{C} / 1\right.$ minuto $+50^{\circ} \mathrm{C} / 2$ minutos $+72^{\circ} \mathrm{C} / 1$ minuto $)$ $+\left(72^{\circ} \mathrm{C} / 7\right.$ minutos $)$. Os produtos de PCR foram separados em gel de agarose $1,5 \%$, acrescido de brometo de etídio e visualizado sob luz UV. Os primers utilizados foram ENV-AS1 anti-sense (5'-ATTGTCACCATAAGCAGCCA-3') e ENV-S1 sense (5'-CAAGCACT'TCTGT'TTCCCCGC-3'), direcionados para a região $5^{\prime}$ - não traduzida do genoma de Enterovirus e que amplificam um produto de $437 \mathrm{pb}^{23}$.

Microssoroneutralização. A realização do diagnóstico sorológico requer amostras pareadas de soro (coletadas na fase aguda da doença e fase de convalescença, respectivamente). Essa técnica é aplicada para detectar anticorpos séricos (IgG). Para realização do teste, são necessárias diluições seriadas dos soros pareados, partindo de 1:8 a 1:1024. 0 painel de antígenos padrões utilizados inclui CV-B1, CV-B2, CV-B3, CV-B4, CV-B5, CV-B6 e E-6, E- 7, E-30. Os antígenos (100 TCD 50/0,1mL) foram acrescentados as placas e estas incubadas por 2 horas a $37^{\circ} \mathrm{C}$. Após o período de incubação, $100 \mu \mathrm{L}$ de suspensão celular de RD (220.000 células $/ \mathrm{mL}$ ) foram distribuídos. As microplacas foram incubadas por 72 horas $\left(37^{\circ} \mathrm{C}\right)$ e observadas no microscópio invertido, a fim de visualizar a neutralização da infectividade viral e o aumento de 4x ou mais no título de anticorpos que é considerado como indicador de soroconversã $0^{9}$.

Nos resultados, as amostras inoculadas em culturas de células RD apresentaram ECP característico de Enterovirus: arredondamento, retração, picnose nuclear, refratilidade e degeneração celular. 0 tempo necessário para observar a positividade na cultura celular foi de 6 dias.

Fluorescência foi observada no citoplasma das células sob a observação no microscópio de epifluorescência a 400x, indicando reação positiva para o sorotipo echovírus 6. IFI foi 
negativo para os outros anticorpos monoclonais. RT-PCR foi realizado a fim de confirmar o gênero $\mathrm{EVH}$. Eletroforese em gel de agarose evidenciou um produto de $437 \mathrm{pb}$, identificando $\mathrm{EVH}$ (Figura 1).

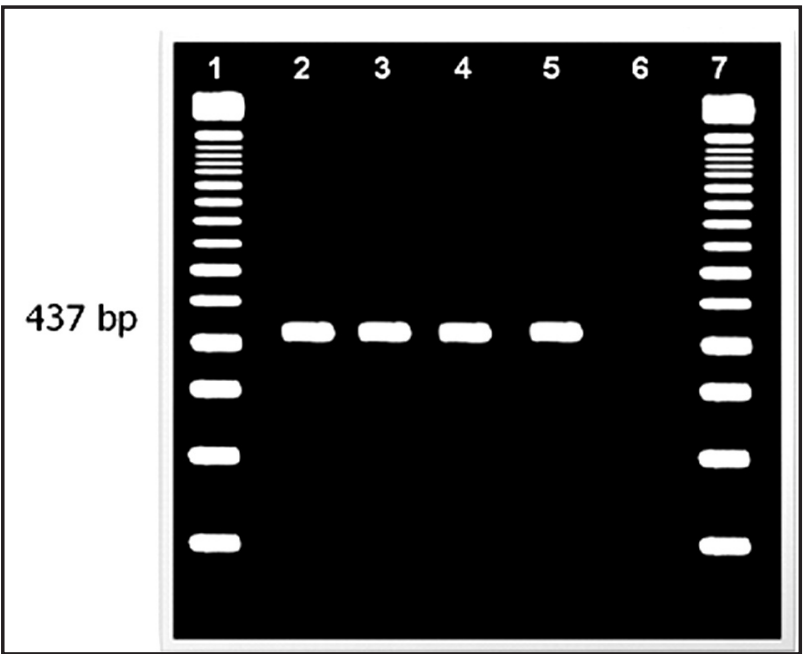

Figura 1 - Transcriptase reversa - reação em cadeia pela polimerase para a região 5 'não transcrita do genoma de Enterovirus isolado em cultura de células. Linhas 2, 3, 4, 5: produto de 437pb amplificado. Linba 6: controle negativo. Linhas 1,7: peso molecular de 100pb DNA.

Em adição, o paciente exibiu soroconversão de anticorpos para E-6, apresentando diluição <1:8 na primeira amostra (fase aguda da doença) e 1:64 na segunda amostra (fase de convalescença). Os títulos para os demais antígenos estão descritos na Tabela 1.

Tabela 1-Resultados da soroconversão no título de anticorpos do paciente com doença exantemática

\begin{tabular}{lcc}
\hline & $\begin{array}{c}\text { 1를 Amostra de soro } \\
\text { (fase aguda da doença) }\end{array}$ & $\begin{array}{c}\text { 2a Amostra de soro } \\
\text { (fase de convalescença) }\end{array}$ \\
\hline CV-B1 & $<1: 8$ & $<1: 8$ \\
CV-B2 & $<1: 8$ & $<1: 8$ \\
CV-B3 & $1: 512$ & $1: 512$ \\
CV-B4 & $<1: 8$ & $<1: 8$ \\
CV-B5 & $<1: 8$ & $<1: 8$ \\
CV-B6 & $<1: 8$ & $<1: 8$ \\
E-6 & $<1: 8$ & $1: 64$ \\
E-7 & $<1: 8$ & $<1: 8$ \\
E-30 & $1: 8$ & $1: 8$ \\
\hline
\end{tabular}

CV: Coxsackievirus B1 a B6, E: Echovírus.

\section{DISCUSSÃO}

Doenças virais estão entre as primeiras causadoras de morbidade em população pediátrica em regiões tropicais. Dentro deste grupo, vírus exantemáticos são especialmente prevalentes ${ }^{3}$. Exantemas virais são comuns na infância, sendo a maioria inofensiva para a saúde da criança, mas em alguns casos podem ser sinais de doenças sistêmicas mais importantes ${ }^{3}{ }^{17}$. Reconhecimento de exantemas é uma maneira importante de prover cuidados primários $^{17}$.

Neste trabalho, o paciente possuía idade inferior a 2 anos e era do sexo masculino. As crianças são de fato, mais atingidas pelas infecções virais que os adultos. Um estudo conduzido nos anos 60 demonstrou que a taxa de ataque de um $\mathrm{EVH}$, echovírus 9 envolvido com doença exantemática foi de 50 a $70 \%$ em crianças mas somente de 17 a 33\% em adultos, fato este que reflete uma maior exposição das crianças ao agente ${ }^{12}$. Entre as crianças, o sexo masculino apresenta o maior risco para desenvolver a infecção por Enterovirus com manifestações clínicas, enquanto infecções assintomáticas são mais comuns no sexo feminino ${ }^{16}$.

0 desenvolvimento da doença descrita nesse relato de caso ocorreu no período de Janeiro, corroborando com os dados disponíveis na literatura onde os Enterovirus apresentam um comportamento sazonal, predominando no verão ${ }^{19}$.

O isolamento de Enterovirus em cultura de células permanece como método padrão ouro para o diagnóstico ${ }^{6}$, permitindo a realização de IFI como também a RT-PCR após a primeira passagem em célula. Esse procedimento é de extrema importância, pois com essas duas metodologias de identificação agiliza-se 0 diagnóstico de Enterovirus, e com isso, possibilita o melhor fluxo na liberação de resultados e conseqüentemente maior qualidade na conduta médica a ser tomada. Vale ressaltar que o isolamento de um echovírus a partir das fezes não necessariamente significa que a doença focal ou sistêmica é devida a este vírus; ele pode ser um vírus transiente não relacionado com a patologia. Por essa razão, a pesquisa de anticorpos através da técnica de soromicroneutralização é o método de escolha empregado para confirmar a relação entre o vírus isolado e a resposta imunogênica apresentada pelo paciente no período da infecção?

Vários tipos de Enterovirus podem causar enantemas e exantemas, mas raramente vesículas: coxsackievírus A (CV-A) 4, CV-A5, CV-A6, CV-A9, CV-A10, CV-A16; CV--B5; E-2, E-4, E-6, E-11, E-16, E-18 e enterovirus 71 (EVH-71) ${ }^{724}$. Exantema vesiculares causados por Enterovirus são similares às lesões provocadas pela doença de mão, pé e boca, mas ocorrem na cabeça, tronco e extremidades. Diferente da varicela essas vesículas não formam pústulas $^{525}$.

Enterovirus são encontrados distribuídos por todo o mundo e provocam uma variedade de exantemas cutâneos, entretanto, com exceção da doença de mão, pé e boca, as manifestações são geralmente indistintas e impossibilitam o diagnóstico baseado apenas no exantema ${ }^{7}$. Embora o exantema por si só não provoque sintomas significativos, ele pode ser usado como marcador para Enterovirus na comunidade 3 . 0 exantema pode ser confundido com outras infecções virais, algumas das quais possuem implicações mais sérias ${ }^{17}$.

E-9 e E-16 são freqüentemente associados com exantema rubeliforme ou mobiliforme e febre baixa. As erupções se iniciam na fase aguda e se disseminam para troncos e pernas ${ }^{2}{ }^{3}$. Além desses dois echovírus, o E-25 também é comumente associado a exantema ${ }^{10}$.

E-6 é reconhecidamente associado à casos de meningite asséptica $^{42127}$, inclusive no Brasil ${ }^{13}$. Durante seus períodos de alta atividade, o vírus está geralmente associado a surtos. As manifestações clínicas incluem meningite asséptica, meningoencefalite, exantemas e doenças gastrointestinais. E-6 é o quinto tipo mais comum de Enterovirus identificado durante 0 
período de 1970 a 2005 nos Estados Unidos, totalizando 6,2\% dos casos reportados com sorotipos conhecidos ${ }^{11}$. E-6 está entre os 4 sorotipos mais prevalentes na Espanha em um estudo realizado de $1988-1997^{26}$. Crianças menores de 1 ano são a fonte mais comum para a detecção de E-6 ${ }^{11}$.

No Brasil, foi descrita uma epidemia de doença exantemática em creche, acometendo 10 crianças de 7 a 13 meses de idade, onde foi isolado $\mathrm{CV}$-B $3^{15}$. Anterior ao presente estudo não há relatos do envolvimento de E-6 em caso de doença febril exantemática descrita no país.

Existem relatos de infecções crônicas ocasionadas por E-6 demonstradas in vitro e in vivo em pacientes com síndrome de fadiga crônica, onde ocorre o aparecimento de vesículas similares a herpesvírus ${ }^{29}$.

Nesses resultados demonstrou-se a presença de E-6 no estado de São Paulo em 2007, associado à doença febril exantemática, confirmando a participação e importância dos echovírus como agente etiológico responsável por essa doença. Este achado enfatiza a importância do diagnóstico diferencial para a elucidação de casos clínicos como o relatado. E a necessidade de intensificação nos estudos epidemiológicos e laboratoriais desse sorotipo e a vigilância para outros sorotipos de HEV envolvidos em doenças exantemáticas no Brasil.

\section{AGRADECIMENTOS}

À Seção de Registro Geral do Serviço de Arquivo Médico e Estatístico (SAME) do Instituto de Infectologia Emílio Ribas, pelo acesso as informações clínicas do paciente.

\section{REFERÊNCIAS}

1. Bastis D, Simonet S, Patterson MA, Neill S. Identifications of Enteroviruses by indirect immunofluorescence using monoclonal antibodies. Clinical and Diagnostic Virology 3: 83-93, 1995.

2. Bell EJ, Ross CAC, Grist NR. ECHO 9 infection in pregnant women with suspected rubella. Journal of Clinical Pathology 28: 267-269, 1975.

3. Carneiro SC, Cestari T, Allen SH, Silva N.R. Viral exanthems in the tropics. Clinics in Dermatology 25: 212-220, 2007.

4. Chomel JJ, Antona D, Thouvenot D, Lina B. Three ECHOviruses serotypes responsible for outbreak of aseptic meningitis in Rhône-Alpes region, France. European Journal Clinical Microbiology \& Infectious Diseases 22: 191-193, 2003.

5. Cohen JI. Doenças infecciosas - enterovírus e reovírus. In : Kasper FL, Fauci AS, Longo DL, Braunwald E, Hauser SL, Jameson JL (eds) Harrison Medicina Interna. MacGraw-Hill interamericana do Brasil, Rio de Janeiro, p. 1200-1205, 2006.

6. Dagan R, Menegus MA. A combination of four cell types for rapid detection of enteroviruses in clinical specimens. Journal of Medical Virology 19: 219-228, 1986.

7. Dechamps C, Peigue-Lafeuille HH, Laveran H, Beytout J, Roger H, Beytout D. Four Cases of vesicular lesions in adults caused by enterovirus infections. Journal of Clinical Microbiology 26: 2182-2183, 1998.

8. Fölster-Holst R. Viral exanthem. Der Hautarzt; Zeitschrift für Dermatologie, Venerologie, und verwandte Gebiete 55: 804-817, 2004.

9. Grandien M, Forsgren M, Ehrnst A. Enteroviruses and reoviruses. In: Lennette EH, Schimidt NJ (eds) Diagnostic procedures for viral and rickettsial diseases, $6^{\text {th }}$ edition, American Public Health Association, Washington, p 513-578, 1989.
10. Hill WM. Are Echoviruses still orphans? British Journal of Biomedical Science 53: 221-226, 1996.

11. Khetsuriani N, LaMonte-Fowlkes A, Oberste S, Pallansch MA, Centers for Disease and Prevention. Enterovirus Surveillance - United States 1970-2005. Morbidity and Mortality Weekly Report 52: 1-20, 2006.

12. Lerner AM, Klein JO, Cherry JD, Finland M. New viral exanthems. The New England Journal of Medicine 269: 678-685, 1963.

13. Luchs A, Russo DH, Cilli A, Costa FF, Morillo SG, Machado BC, Pellini ACG, Carmona RCC, Timenetsky MCST. Echovirus 6 associated to aseptic meningitis outbreak in São Joaquim da Barra, São Paulo, Brazil. Brazilian Journal of Microbiology 39: 28-31, 2008.

14. Melnick JL. Field's Virology. In: Fields BN, Knipe DM, Howley PM, Chanlock RM, Melnick JL, Monath TP (eds) Enteroviruses: polioviruses, coxsackieviruses, echoviruses and newer Enteroviruses, $3^{\text {rd }}$ edition, Lippincott-Raven Publishers, Philadelphia, USA, p. 655-712, 1996.

15. Moreira RC, Castrignano SB, Carmona RC, Gomes FM, Saes SG, Oliveira RS, Souza DF, Takimoto S, Costa MC, Waldman EA. An exanthematic disease epidemic associated with Coxsackievirus B3 infection in a day care center. Revista do Instituto de Medicina Tropical de São Paulo 37: 235-238, 1995.

16. Morens DM, Pallansch MA. Epidemiology. In: Rotbart HA (ed) Human Enterovirus Infections, $1^{\text {st }}$ edition, American Society for Microbiology, Washington, p. 3-23, 1995.

17. Nelson JS, Stone MS. Update on selected viral exanthems. Current Opinion in Pediatrics 12: 359-364, 2000.

18. Oberste MS, Maher K, Williams AJ, Dybdahl-Sissoko N, Brown BA, Gookin MS, Peñaranda S, Mishrik N, Uddin M, Pallansch MA. Species-specific RT-PCR amplification of human enteroviruses: a tool for rapid species identification of uncharacterized enteroviruses. The Journal of General Virology 87: 119-128, 2006.

19. Peres LV, Carvalhanas TRMP, Barbosa HA, Gonçalves MIC, Timenetsky MCST, Campeãs AE. Meningite Viral. Disponível em http://www.cve.saude.sp.gov. br/agencia/bepa30_menviral.htm. Acesso em 7 de março de 2008.

20. Ramsay M, Reacher M, O'Flynn C, Buttery R, Hadden F, Cohen B, Knowles W, Wreghitt T, Brown D. Causes of mobiliform rashe in a higly imunised English population. Archives of Disease in Childhood 87: 202-206, 2002.

21. Rodríguez MAG, Comas LG, Garduño IR, Fernández CG, Gavín MO, Fernández RR, Red de Vigilancia Epidemiologic de la Comunidad de Madrid. Increase in viral meningitis cases reported in the Autonomous Region of Madrid, Spain, 2006. Euro Surveillance: bulletin européen sur les maladies transmissibles 11: E061103.3, 2006.

22. Rotbart HA. Enzymatic RNA amplification of the Enteroviruses. Journal of Clinical Microbiology 28: 438-442, 1990.

23. Rotbart HA, Hayden FG. Picornavirus infections: a primer for the practitioner. Archives of Family Medicine 9: 913-920, 2000.

24. Santos NOS, Romanos MTV, Wigg MD. Introdução a Virologia Humana. In: Gonçalves JLS, von Hunbinger MG, Wermelinger MCMW (eds) Viroses do Sistema nervoso Central, $1^{\circ}$ edição, Guanabara Koogan AS, Rio de Janeiro, 2002.

25. Scott LA, Stone MS. Viral exanthems. Dermatology Online Journal 9: 4, 2003.

26. Stanway G, Brown F, Christian P, Hovi T, Hyypiä T, King AMQ, Knowles NJ, Lemon SM, Minor PD, Pallansch MA, Palmenberg AC, Skern T. Family Picornaviridae. In: Fauquet CM, Mayo MA, Maniloff J, Desselberg U, Ball LA (eds) Virus taxonomy---classification and nomenclature of viruses. $8^{\text {th }}$ report of the International Committe on the Taxonomy of Viruses. Elsevier Academic Press, Amsterdam, The Netherlands, p. 757-778, 2005.

27. Thoelen I, Lemey P, Van Der Donck I, Beuselinck K, Lindberg AM, Van Ranst M. Molecular typing and epidemiology of enteroviruses identified from an outbreak of aseptic meningitis in Belgium during the summer of 2000. Journal of Medical Virology 70: 420-429, 2003.

28. Trallero G, Casas I. Tenório A, Echevarria JE, Castellanos A, Lozano A, Breña PP. Enterovirus in Spain: virological and epidemiological studies over 10 years (1988-97) Epidemiology and Infection 124: 497-506, 2000.

29. Yousef GE, Bell EJ, Mann GF, Murugesan V, Smith DG, McCartney RA, Mowbray JF. Chronic enterovirus infection in patients with postviral fatigue syndrome. Lancet 1: 146-150, 1988. 